O. Gingerich: Yes, there was a whole genre of this form of book. In England there was even The Ladies Almanac; in it William Herschel first appeared in print.

\title{
INTRODUCTORY ASTRONOMY TEXTBOOKS IN 19TH AND 20TH CENTURY AMERICA
}

\author{
Norman Sperling \\ Chabot Observatory, 5248 Lawton Avenue, Oakland, California 94618, U.S.A.
}

\section{Introduction}

A survey of 138 introductory-astronomy textbooks spanning 152 years reveals growing consensus regarding each topic's proportion, with some clearly gaining space at the expense of others. The tables in the texts cite curious numbers, claim too many significant digits, neglect to note uncertainties, and are frequently inconsistent with, or badly behind, the research of the times. This study investigates apportionment of topics, planet and star data tables, and categorization of nebulae.

To probe the student/textbook interaction, I used one copy of each of 40 recent introductory textbooks when teaching astronomy in Fall 1986. Students swapped books each session. 'Texts' treatments were surveyed in daily recitation as well as term papers comparing and contrasting them on specific topics. Most books sound much more positive than current data justify. There was lots of confusing phrasing, shoddy proofreading, and careless assembly of data tables. A few books are shamefully erroneous. There are numerous impressive examples of the imperfection and transience of "textbook learning." The biggest and most pervasive sin was writing in the passive voice "Official Style" of interminable sentences laden with prepositional phrases. Illustrations, while important, are secondary to phrasing. Students need and use chapter summaries, glossaries, and indices. About half prefer paperbacks and half hardbacks. Students rated the books for appropriateness to their needs. The experience may stimulate others to develop controlled experiments to probe the student/textbook interaction.

\section{Topics in Textbooks}

A text is a worthy, good-faith reference, but in 20 years it will be hopelessly inadequate, and in 100 years, laughable. As knowledge of astronomy has grown, so has the number of topics and the amount of data that could be presented. Thus, the proportions of various topics have changed over the centuries. The accompanying graph demonstrates some of the changes. 
Indices can also be derived by dividing one portion by another. Stellar divided by positional shows a dramatic growth. Thus, modern stellar astronomy horned into textbooks by shoving aside older topics such as positional astronomy. Conversely, (asteroids + comets + meteors) divided by (nebulae + clusters + galaxies + cosmic) plummets strikingly. As the space devoted to the universe beyond the stars grew, it did so largely at the expense of older, less-spectacular topics like solar system debris.

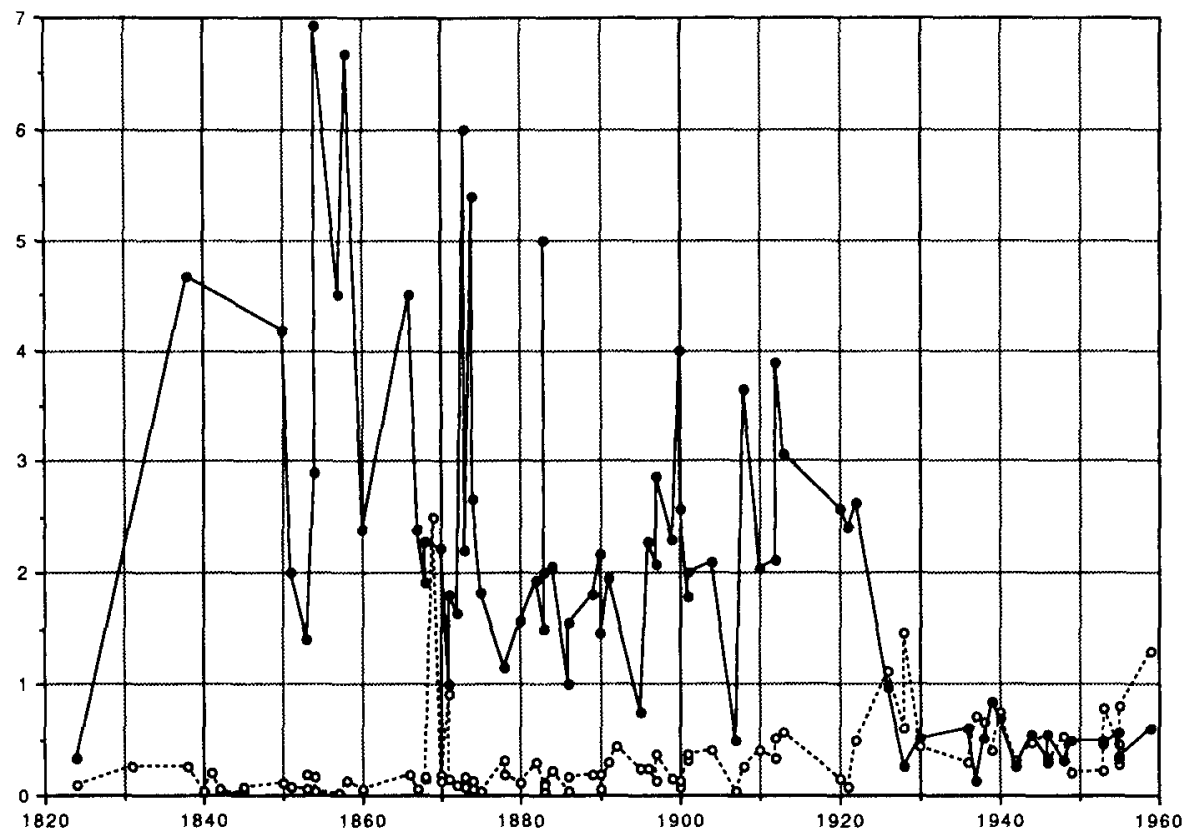

A graph of the changing stellar/positional (open circles) and solar system debris/ beyond stars (filled circles) in introductory astronomy textbooks in America.

Most topics show a narrowing of the scatter, demonstrating a strong regimentation about the relative proportions - though their arrangement has always been various, and remains so today.

Most books include data tables for planetary orbits and physical characteristics, and recent ones include tables of the nearest and brightest stars. The data are strikingly varied! Since only a few independent determinations of diameters and rotations had been made, it is very curious to find such a spread in quotations. Some may result from poor proof-reading and negligent copying. Too few authors told their readers that the data weren't as definite as the numbers implied - and too few still do.

Classification is one of science's most fundamental techniques for coping with nature's diversity. We owe it to our students to show them how science categorizes celestial phenomena. A problem gaining prominence when this run of texts begins, 
and retaining it through the present, has been how to categorize the "nebulae." Categories of nebulae that became resolved as clusters were the first to go, but didn't leave textbooks until the 1880 s - many decades after relegation by the astronomers at the forefront! Galaxies were recognized as such by about 1928 , but didn't lose the term "extragalactic nebulae" until 1940, when they were carved off and given their own sections as galaxies.

The only category of nebula that has survived from beginning to present is "planetary." However, three other categories have been merged into it: stellar nebulae into nebulous stars before 1880 , nebulous stars into planetaries about 1910 , and ring or annular nebulae into planetaries in the mid 1920s.

As technology has progressively brought giant telescopes, spectroscopy, and photography into play, understanding has undergone several paradigm shifts. Categories, such as those most popular at present, did not all spring up together: dark nebulae entered the texts after 1920 , the interstellar medium in the late 1940s, reflection and emission nebulae about 5 years later, and supernova remnants in the mid-1960s. However, category sets may fairly often disappear sharply.

Though most nebular categories sound pretty familiar, specific objects we all use to exemplify those types have not always been considered thus. Messier 31 in Andromeda exemplified elliptical or oval nebulae from the 1830s to the turn of the century. Greater light-gathering power in the mid-1800s portrayed it as irregular instead, as reported in several texts from 1870 to 1912 , and a couple in the mid1800 s even called it annular. Photography recast it as a spiral before the end of the 1800 s, with most books calling it so after the turn of the century.

\section{Students' Views of Existing Textbooks}

A 1986 experiment which I conducted sought to learn what students think of textbooks, and what differences among texts are important. Every student came to understand that textbooks are fallible, because in the course of the semester every student had books with obvious faults. Several students applauded personal notes, and narratives of science as process instead of "pat" answers.

I was definitely confirmed in my long-standing objection to books that sound too "positive." Those become the most hilarious at age 100, but they're also misleading right now. In the drive to tell the student what astronomy has learned, most authors declare "truths" that aren't all that firmly pinned down. One student logged all the data her assorted books quoted about Pluto, and found not only the spread in data but also mysterious variations, even in long-established quantities like orbital inclination and apparent magnitude. She also spotted typographical errors in decimal places - which, of course, make the data wrong by factors of 10 . Who verifies all those data tables? The students concluded:

1. Paramount is the ease of reading, particularly for weak students. "Official passive" voice is deadly! Interminable sentences laden with prepositional phrases definitely inhibit reading, and turn off marginal students.

2. Chapter-end summaries are very useful. Chapter-end questions challenge some 
students, frustrate others, and are skipped by most except when assigned. Weak students depend heavily on glossaries, and all need a thorough, competent index. The rest of the chapter-end and appendix material was less important. (Personally, I recommend keeping the "further readings" listings if only to demonstrate that such exist.)

3. Students view being "up-to-date" more as the teacher's responsibility than the book's.

4. Ilustrations are very useful (the less-well-illustrated books were less-wellremembered) but didn't actually sell them. Students will be hard-pressed to identify anything in the sky from the star charts in most books.

Two books placed head-and-shoulders above all others: Zeilik and Pasachoff. But what I'd really like is a textbook with Zeilik's personal flair, lively language, and thorough history; Pasachoff's passionate accuracy and marginal notes; Snow's 3rd edition's color; Kaufmann's thoroughness; Friedlander's cautions; Shu's feel for the physics; Robbins' and Jeffreys' observing; Hartmann's art - and my outline.

Table 1: How Appropriate My students Thought Each Book Was ${ }^{a}$

\begin{aligned} & 3.375-3.5: Pasachoff; Zeilik \\ & $2.78-2.9:$ Abell; Friedlander; Goldsmith; Hartmann; Kaufmann; Parker \\ & $2.44-2.57:$ Bash; Dixon; Field, Verschuur, and Ponnamperuma; Long; \\ & Protheroe, Capriotti, and Newsom; Seeds \\ & $2.17-2.3:$ Berman and Evans; Chapman; Jastrow and Thompson \\ & $1.5-2.0:$ Apfel and Hynek; Branley, Chartrand, and Wimmer; Cole; \\ & Devinney, Smith, and Sofia; Hodge; Hoyle; Jefferys and Robbins; \\ & King; Pananides and Arny; Shu; Snow ${ }^{b}$ Wyatt \\ & 0.625-1.25: Brandt and Maran; Clotfelter; Ebbighausen; Oriti and Starbird \\ & \hline\end{aligned}

${ }^{a}$ Scored as conventional grades: excellent $=4$; good $=3$; adequate $=2$; barely $\mathrm{OK}=1$; unacceptable $=0$.

${ }^{b}$ Probably influenced by instructor's negative comments.

I hope these experiences will provoke other instructors to probe student/textbook interactions. Can someone design rigorous, controlled experiments with assorted books, formats, and types of students?

\section{Discussion}

T. Dennis: When do you see problem sets appear, and can you tell if they are meant to be solved by the student, or are they just there?

N. Sperling: If you count predecessors of textbooks, the discourses on the use of globes: my oldest (Moxon, 1674) has copious problems for each student. Problems 
clearly predate Moxon. As discourses on globes incorporate the rest of astronomy, they keep the problems about the globes, and during the 1700 s become more about the cosmos and its workings, and less about globes. My (very few) 1700s British texts have many "examples" but no "problems" beyond globes. My earliest American texts (1820s) have lots of problems all through. Problems abound in them ever since.

B.W. Jones: This might seem a silly question, but how did you decide, particularly for the older books, which were textbooks, i.e., how did you prepare your sample?

N. Sperling: On the basis of the stated goals of the author of the book.

\section{TEXTBOOKS: A PANEL DISCUSSION}

\section{Textbooks for Developing Countries}

\section{Mazlan Othman}

Physics Department, Universiti Kebangsaan Malaysia

43600 UKM, Bangi, Selangor D.E., Malaysia

I would like to address the issue of textbooks from a developing country's point of view.

Firstly, I believe that in the developing countries a textbook should be written in the native language if it is to reach the very people whose awareness of astronomy needs to be raised. And when we talk about books in the vernacular, the problem is one of dearth: a dearth of writers and a dearth of resources.

The lack of writers comes about simply because in the developing nations there are inevitably very few astronomers and of these only one or two will be inclined to write books. If there exist writers, they are faced with several choices and problems. There are three types of books which can be written: a university text, a school text, and I shall include a book for the public. Each type of book targets a different kind of audience, so the writer must be attuned to the needs of the nation to know what the priority should be. If, for example, astronomy is about to be introduced into a school curriculum, then a school textbook should take the highest priority because it tackles astronomy education at the grass-roots level. Naturally, the final choice will depend on other factors as well, including promotion, fame, and pecuniary considerations.

A more intractable problem for the developing countries is one of getting materials for the book. Photographs are properties of big observatories or individuals and special permission must be sought to use them. Personal contact is the only 